\title{
放牧および舎飼期における肉用子牛の発育に対するパーム油 脂肪酸カルシウムの添加給与の効果
}

\author{
櫛引史郎* ·梅村和弘 - 寺田隆慶 - 林 孝**
}

農林水産省草地試験場山地支場，長野県御代田町 389-02

(1997. 11. 20 受付)

肉用子牛の放牧育成は，環境感作や要動量の增大なよ゙ 增体にマイナスに㗢く要因が存在する゙1)ことから，今な 扣発育改善のための実用的な飼養技術の開発が求められ ている、放牧铝垠はエネルギー不足・タンパク質過剩 ${ }^{13)}$ 等を招きやすく, マクロミネラルのアンバランスは施耽 管理等によって部分的には改善されても尚，いま一層の 発育の改善には土ネルギーの増給が必要である る $^{8,9)}$.

そこで本研究では, 哺乳子牛のようにルーメンが発達 中で乾物摄取量が少ない時期》に扔けるエネルギー補給 を，パーム油脂肪酸 Caの添加給与により促進するこ上 を検討した。

\section{材料および方法}

\section{1. 供試動物 と飼料}

草地試験場山地支場で生産された黒毛和種子牛延心゙ 60 頭を添加区之無添加区に分けて供詰した。試駼期は哺 乳期之育成期の 2 期である. 試験開始時の子牛の平均日 齢は添加区 $52.4 \pm 10.4$ 日，無添加区 $52.2 \pm 10.8$ 日であっ た.

添加区には基礎飼料に脂肪酸 Caを添加したものを別 飼飼料として，無添加区には基碟飼料のみを別飼飼料と して給与した，基礎飼料は市販の配合飼料（TDN： $74 \%, \mathrm{DCP}: 9.5 \%$, 粗脂肪: $2.0 \%, \mathrm{Ca}: 0.5 \%)$ を, 脂肪 酸 Caにはペレットに加工した市股品（Volac 社製，

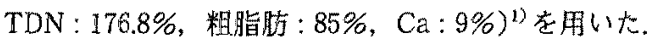

\section{2. 試験期}

哺乳期恃面皘 9.3 ha の放牧專用草地を 2 等分し，それ ぞれに添加区，無添加区の親子組を昼夜放牧した。試験 期間は 16 週間，暦月では 7 月下旬から 11 月上旬までで
ある，別飼飼料は群に対して乾物で1日当たり体重の 1\%を給与した，脂肪酸 Caは添加区の基礎飼料に対し て乾物で $5 \%$ を添加した。体重測定は每週行い，試験開 始時之終了時には体高を測定した。子牛は哺乳期の放牧 終了後に音舎に叹容して離乳，雄子牛は去勢した。

育成期の試験開始は 11 月中旬（約 24 週戟）とし，翌 年 4 月中旬までの 21 週間を舎内群飼とした。基礎飼料 之脂肪酸 $\mathrm{Ca}$ は喃乳期上同じである。別飼飼料（基礎飼 料十添加脂肪酸 $\mathrm{Ca}$ ）は乾物で 1 日当たり体重の $1 \%$ を 給与, 乾草 (TDN : $46 \%$, Ca: $0.39 \%)^{10)}$ 估鉋食させた。 脂肪酸 $\mathrm{Ca}$ は日本飼養䅺準(10) 加ら求的た採食見込み乾物 量（基礎飼料十乾草）の5\%量を同量の基礎飼料之置き 換えて添加，混和した．体重測定は隔週で行い，試験終 了時に体高を測定した。

\section{3. 統計処理}

各試験期の脂肪酸 Ca の添加給与の効果は, 次のモデ ルで解析した。

$$
\begin{aligned}
\mathrm{Y}_{h i j k l}= & \mu+\mathrm{S}_{\mathrm{h}}+\mathrm{T}_{\mathrm{i}}+\mathrm{R}_{\mathrm{k}}+\mathrm{X}_{S T \mathrm{hi}}+\mathrm{X}_{\mathrm{T} \mathrm{ij}} \\
& +\mathrm{X}_{\mathrm{TRik}}+\beta \mathrm{D}+\mathrm{e}_{\mathrm{hijkl}}
\end{aligned}
$$

ここで, $\mathrm{Y}_{\mathrm{nijk}}$ : 测定值 (体重, 日增体量, 体高, 伸長), $\mathrm{S}_{\mathrm{h}}: \mathrm{n}$ 番目の性の効果, $\mathrm{T}_{\mathrm{i}}:_{\mathrm{i}}$ 番目の処理の効果, $\mathrm{R}_{\mathrm{k}}: \mathrm{k}$ 番 目の年次の效果, $\beta$ : 回帰係数, $D$ : 開始時日龄である.

\section{結果および考察}

表 1 に試験期に求ける子牛の体重と飼料掑取量として TDN の推定摄取量を示した。哺乳期では，12週目まで の両区の体重に大きな差は認められなかったが，16 週目 には添加区加無添加区を上回った，基礎飼料の掫取量 は, 週の経過にとともに增加し，16週目には両区で体重

* 現所属：農林水産省東北農業試験場，盛岡市 020-01

**兒所属：農林水産省畜産試験場，茨城県筑波農林研究団地 305 
の1\%を提取するようになった，添加区の脂肪酸 $\mathrm{Ca}$ の 摄取量は，基礎䬧料の摄取量と之屯に增えた。 TDNの 推定摄取量は，8 週日以降添加区が無源加区を上回り， 16 週目には前者は後者より約 19\%高まった，育成期に は両区の体重差はいっそう広がったが，両区の乾草掁取 量は体重の 1.0 1.1\%の匴囲であった. TDNの推定摄
取量は添加区が無源加区を上回って推移し，乾物摄取量 に対する脂肪酸 Ca の割合は，ほぼ一定の $5 \%$ であった。

表 2 には哺乳期は雄に，育成期は去勢に補正した各測 定値の試験期終了時における最小二乗平均值を示した。 体重、日增体量（DG）、体高おょび伸長について哺乳期， 育成期ともに添加区は無添加区よりも脂れた，脂肪酸

Table 1. Average intake of concentrate, Ca-soap and hay per day per calf during suckling and raising term

\begin{tabular}{|c|c|c|c|c|c|c|c|}
\hline \multirow{2}{*}{$\frac{\text { Term }}{\text { Suckling }}$} & \multicolumn{4}{|c|}{$5 \%$ added $\mathrm{Ca}-\mathrm{soap}$} & \multicolumn{3}{|c|}{ Control } \\
\hline & $\begin{array}{c}\text { Body weight } \\
(\mathrm{kg})\end{array}$ & $\begin{array}{l}\text { Concentrate } \\
(\mathrm{DM} \mathrm{kg})\end{array}$ & $\begin{array}{l}\text { Ca-soap } \\
(\mathrm{DM} \mathrm{kg})\end{array}$ & $\begin{array}{c}\text { TDN intake } \\
(\mathrm{kg})\end{array}$ & $\begin{array}{c}\text { Body weight }{ }^{1)} \\
(\mathrm{kg})\end{array}$ & $\begin{array}{l}\text { Concentrate } \\
\text { (DM kg) }\end{array}$ & $\begin{array}{c}\text { TDN intake } \\
(\mathrm{kg})\end{array}$ \\
\hline $0 \mathrm{w}$ & $64.0 \pm 14.2$ & & & & $67.1 \pm 14.0$ & & \\
\hline $4 w$ & $89.2 \pm 14.8$ & 0.21 & 0.01 & 0.20 & $91.3 \pm 15.9$ & 0.23 & 0.20 \\
\hline $8 w$ & $111.6 \pm 18.0$ & 0.68 & 0.03 & 0.63 & $111.4 \pm 19.4$ & 0.67 & 0.57 \\
\hline $12 \mathrm{w}$ & $133.0 \pm 19.0$ & 1. 24 & 0.06 & 1.17 & $130.7 \pm 20.6$ & 1.19 & 1.01 \\
\hline $16 w$ & $153.1 \pm 19.2$ & 1.53 & 0.08 & 1.45 & $143.4 \pm 21.1$ & 1. 43 & 1. 22 \\
\hline Raising & $\begin{array}{c}\text { Body weight }{ }^{1)} \\
(\mathrm{kg})\end{array}$ & $\begin{array}{c}\text { Hay } \\
(\mathrm{DM} \mathrm{kg})\end{array}$ & $\begin{array}{l}\text { Ca-soap } \\
(\mathrm{DM} \mathrm{kg})\end{array}$ & $\begin{array}{c}\text { TDN intake } \\
(\mathrm{kg})\end{array}$ & Body weight ${ }_{(k g)}$ & $\begin{array}{c}\text { Hay } \\
(\mathrm{DM} \mathrm{kg})\end{array}$ & $\begin{array}{c}\text { TDN intake } \\
(\mathrm{kg})\end{array}$ \\
\hline $23 \mathrm{w}$ & $177.2 \pm 21.9$ & 2.0 & 0.18 & 2.84 & $167.2 \pm 23.8$ & 1.8 & 2.46 \\
\hline $31 w$ & $216.9 \pm 24.7$ & 2.4 & 0.23 & 3. 46 & $198.9 \pm 27.0$ & 2.2 & 2.96 \\
\hline $38 w$ & $273.7 \pm 28.9$ & 2.7 & 0.27 & 4. 15 & $242.8 \pm 28.7$ & 2.5 & 3.50 \\
\hline
\end{tabular}

1) Mean士S.D.

2) Estimates of average feed intake of concentrate, Ca-soap and hay.

Table 2. Least square means \pm Standard error for body weight, withers height, DG, WHG and $\mathrm{BW} / \mathrm{WH}$ ratio at suckling and raising term

\begin{tabular}{|c|c|c|c|}
\hline Items & & $5 \%$ added $\mathrm{Ca}-\mathrm{soap}$ & Control \\
\hline \multirow{2}{*}{$\mathrm{BW}^{1)}$} & $\mathrm{ST}^{2)}$ & $159.0 \pm 3.2^{* *}$ & $148.0 \pm 3.2$ \\
\hline & $\mathrm{RT}$ & $289.2 \pm 5.5^{* * *}$ & $254.0 \pm 5.7$ \\
\hline \multirow{2}{*}{ DG } & ST & $0.90 \pm 0.02^{* * *}$ & $0.76 \pm 0.02$ \\
\hline & $\mathrm{RT}$ & $0.90 \pm 0.02^{* * *}$ & $0.74 \pm 0.02$ \\
\hline \multirow{2}{*}{ WH } & $\mathrm{ST}$ & $98.6 \pm 0.4^{*}$ & $97.1 \pm 0.3$ \\
\hline & $\mathrm{RT}$ & $113.3 \pm 0.6^{* * *}$ & $108.9 \pm 4.4$ \\
\hline \multirow{2}{*}{ WHG $(\mathrm{cm})$} & $\mathrm{ST}$ & $23.8 \pm 0.4^{* * *}$ & $21.7 \pm 0.3$ \\
\hline & $\mathrm{RT}$ & $14.9 \pm 0.7^{* *}$ & $12.0 \pm 0.7$ \\
\hline \multirow{2}{*}{$\mathrm{BW} / \mathrm{WH}$} & $\mathrm{ST}$ & $1.62 \pm 0.03^{* *}$ & $1.52 \pm 0.03$ \\
\hline & $\mathrm{RT}$ & $2.56 \pm 0.04^{* * *}$ & 2. $32 \pm 0.04$ \\
\hline
\end{tabular}

All estimates are corrected by male sex.

1) Abbreviated notations are as follow; BW, body weight; DG, daily gain ; WH, withers height; WHG, withers height gain; BW/WH, body weight $/$ withers height ratio.

2) Abbreviated notations are as follow; ST, suckling term ; RT, raising term.

${ }^{*} \mathrm{P}<0.05,{ }^{* *} \mathrm{P}<0.01,{ }^{* * *} \mathrm{P}<0.001$. 
Ca の添加効果は，試験期を通じて DG 上体高の伸長に 顕著にあらわれ，とくに放牧柌養した哺乳期は，従来の 別䋒効果 ${ }^{5)}$ をきく上回る発育を示した。

これまでに脂肪酸 $\mathrm{Ca}$ を子牛に添加給与した報告は少 なく, Fallon et al ${ }^{2)}$ は，添加割合の上昇と之もに乾物摄 取量之增体量が減少したこと加ら，子牛用飼料への脂肪 添加は望ましくないと述べている。，一方，Jaster et al. ${ }^{4}$ 出，全乳㧍よび代用乳への源加給与は DG を高め，乾物 摄取量の低下は諗めなかったと報告している。本研究で みられた DGの改善効果は，これらの報告とは試験設計 が翼なるために直接的な比較は難しいが, 表 1 に示した ようにTDN 摄取量すなわちエネルギー撕取量の堌加に 起因すると思われる、哺乳期の別飼飼料の提取量は 8 遇 (100日龂) 以降に高まっているが，この時期は哺乳星が

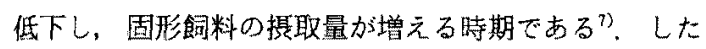
がって，添加区は別飼飼料の摸取量が增加してTDN 摄 取量が多くなった結果，DGが筫添加区を大きく上回っ たと考えられる。巟成期は期間を通じて添加区の TDN 摄取量が無添加区を上回っており，脂肪酸 $\mathrm{Ca}$ の添加給 与によるDGへの影響は，哺乳期と同様にエネルギ一摄 取量の差が反映された結果と考えられる。なお，試験期 間を通して下㢉などの治療を要する症状を呈した涸体は 認められなかった。

脂肪酸 $\mathrm{Ca}$ の添加効果は体高の伸長にも認められた。 試験期を通じた添加区の体高の伸びは，然源加区に比べ て約 14.8\% 向上した。こてれは脂肪酸 Caがエネルギー摄 取量を高めたことと，Caの供給源として働いたことが 推察される. 添加区における固形飼料加らの Ca 掑取量 (うち，脂肪酸 $\mathrm{Ca}$ からの撖取量）は，表 2 からの推定で. 16 週は約 $14.8(8.0) \mathrm{g}, 38$ 週は乾草を含めて約 54.0 (27.0) g टなる。こ林の発育ステージに㧍けるCaの 姴求量 ${ }^{(0)}$ は，それぞれ $26.0 \mathrm{~g}, 33.0 \mathrm{~g}$ 前後であるからら, 脂 肪酸 $\mathrm{Ca}$ は， Ca の供給源しして大きな要因であったと考 えられる。幼撂期におけるCaの吸收率は 90\%在越え る 年方，年龄，飼料および飼料中の含有量などによって

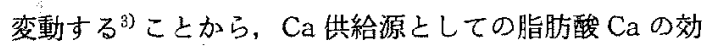
果; そしてパーム油以外の脂肪酸 $\mathrm{Ca} の$ 発育への影響等 をさらに検討する必要がある。

栄養状㮩の指標の一つである体重/体高此㹥, 黒毛和

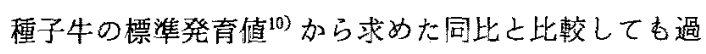
肥の傾问は認められず, 添加区の発育は体高の伸長走之 あなった増体量の増加を示した。飼料への油脂の添加は

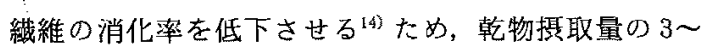
$5 \%$ が適正割合 ${ }^{21)}$ とされているが，パーム油脂肪酸 Ca は乾物昹取量の $5 \%$ までであれば発有への効果が期待で
きると考豆られる、しかしながら，舍飼中心の育成なら びに添加割合の增加は，過肥や粗飼料摄取量の低下等の 生じる可能性が高くなることが報告されている゙、10).

以上より，パーム油脂肪酸 $\mathrm{Ca}$ は，子牛の放牧育成な らびにその後の飼い直し期に放いて有効なエネルギー添 加飼料であることが示唆された。

謝辞

本研究に多大なご協力をいただいた草地試験場山地支 場山地草地研究室（現中国農業試験場畜産部草地飼料作 物研究室) 井出保行圭任研究官に，家畜管理を担当され た業務科の各技官に深謝します。

\section{文献}

1) 阿部又信・入来常微・舟場正幸、䁕肪酸カルシウ 么塩の TDN 含量. 日畜会報, $63: 60-65.1992$.

2) Fallon RJ, Williams PEV, Innes GM. The effects on feed intake, growth and digestibility of nutrients of including Calcium soaps of fat in diets for young calves. Anim. Feed Sci. Technol., 14: 103-115. 1986.

3) Horst RL. Regulation of calcium and phosphorus homeostasis in the dairy cow. J. Dairy Sci., $69: 604-616.1986$.

4) Jaster EH, Mccoy GC, Fernande RL. Dietary fat in milk replacers for Dairy calves raised in hutches during the winter. J. Dairy Sci., 73 : 1843-1850. 1990.

5）櫛引史郎・梅村和弘・林孝. 成長モデルを含 む線形モデルによるクリープ飼料の効果の解析. 日畜会報, $62: 69-75.1991$.

6）櫛引史郎・梅村和弘・林孝、放牧地に扔ける 施盵管理が肉用繁殖雌牛の血獎ミネラル成分に及 ぼす影響. 草地試験場研究報告, 45：93-103. 1991.

7） 久馬 忠・菊池武昭・高橋政義・滝沢静雄．黑毛 和種自然哺乳子牛の摄取生態之栄養摄取量. 東北 農業試墦場研究報告, 52:145-159. 1976.

8） 久馬 忠・潼沢静雄・高橋政義・菊池武昭. 子牛 のクリープフィーデング法の検討. (1) 給与䬲料 の栄養組成について，日畜東北支部会報， $30: 17-$ 18. 1980.

9) Martin TG, Lemenager RP, Srininasan G, Alenda R. Creep feed as a factor influencing of cows and calves. J. Anim. Sci., $53:$ 33-39. 1981.

10）農林水産省農林水限技術会議事務局。日本飼養標 準肉用牛。中央音産会. 東京. 1987.

11) National Research Council. Effect of environment on nutrient requirements of domestic animals. National Academy Press. 
Washington, D.C. 1981.

12) Palmquist DL, Jenkins TC. Fat in lactation rations : Review. J Dairy Sci., 63 : 1-47. 1980.

13）任藤 博・砂子田哲・杉若辉夫・佐藤彰芳・三 浦由雄. 泌乳牛の放牧初期に扎洫洯成分の变 化，日畜会報，52：874-877。1981。
14) Ward JK, Tefft CW, Sinry RJ, Edwards HN, Tillman AD. Further studies concerning the effect of alfalfa ash upon the utilization of low-quality roughage by ruminant animals. J. Anim. Sci., 16 : 633-638. 1957.

\title{
The Effects of Calcium Soap Supplement on Growth Response of Beef Calves during Grazing and Housing Period
}

\author{
Shiro KUSHIBIKI*, Kazuhiro UMEMURA, \\ Takayoshi TERADA and Takashi HAYASHI** \\ National Grassland Research Institute Alpine Region Branch, \\ Miyota-machi, Nagano-ken 389-02
}

\begin{abstract}
Sixty calves of Japanese Black were used to evaluate the effects of calcium soap of palm oil on the growth response during suckling and raising period. The calves were grazed and suckled by their dams from 7 to 16 weeks of age. After rearing, the calves were feed in house from 17 to 38 weeks of age. Control group of calves could take creep feed (TDN : 74\%, DCP : 9.5\%,CFat : $2.0 \%$ ) in grazing period. The creep feed containing $5 \%$ calcium soap (TDN : $176 \%$, Ca : 9\%) were fed to treated group of calves. The concentrates with or without calcium soap were fed $1 \%$ of body weight to both the groups in raising period. Daily weight gain (DG) and withers height gain of calves fed supplemental calcium soap were higher $(\mathrm{P}<0.001)$ than control group in grazing and raising term. Dominance on the DG and withers height gain of the supplemented group was due to the increase in energy intake in both through the experiment period.
\end{abstract}

Anim. Sci. Technol. (Jpn.) 68 (10) : 983-986, 1997

Key words : Calf, Growth, Calcium soap

* Present address : Tohoku National Agricultural Experimental Station, Morioka-shi 020-01

** Present address : National Institute of Animal Industry, Tsukuba Norin Kenkyu Danchi, Ibaraki-ken 305 